\title{
Assim como nasce um bebê, nasce uma mãe? Para além da depressão pós-parto
}

CRONEMBERG, Lorena; FRANCH, Monica. Ser mãe é padecer no paraíso? Narrativas de depressão pós-parto. João Pessoa: Editora UFPB, 2020.

Rosamaria Carneiro (https://orcid.org/0000-0002-1271-7645), Departamento de Saúde Coletiva da Universidade de Brasília (UnB), Brasília, Distrito Federal, Brasil'.

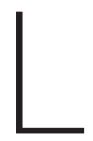

orena Cronemberg e Monica Franch nos inserem no debate sobre a depressão pós-parto no Brasil por meio de uma miríade complexa e original de olhares. Por isso, muitos sãos os méritos do livro para o campo dos estudos feministas, de gênero, das maternidades/maternagens, da vida social do cuidado em geral e para os campos da saúde e sexualidade, bem como da saúde mental. Nesse sentido, é uma obra que conjuga muitos campos e que os coloca em intersecção a partir da ideia de depressão pós-parto (DPP). Realiza tal proeza, entretanto, não a partir de um Código Internacional de Doenças (CID) ou de teorias psicanalíticas e/ou psicologizantes da subjetividade das mulheres, mas a partir da narrativa das próprias mulheres. Daquelas que tiveram ou disseram ter vivenciado essa experiência.

Desta feita, inova por conta de, por si só, abordar tema silenciado de maneira geral; de retirá-lo das ciências psi e da saúde e inseri-lo no debate antropológico e sociológico, nos quais é ainda pouquíssimo explorado. Em razão de se desenrolar a partir das narrativas das mulheres e, por último, em virtude de descentrar a própria ideia de DPP, dando-Ihe novos contornos semânticos e sociais, a partir da noções de cansaço, exaustão, desempenho e solidão. Suas páginas tornam a DPP ordinária e cotidiana, retirando-a da ordem da loucura e da patologia hormonal. Ao alojá-la no dia a dia de mães de camadas médias brasileiras afeitas a "teorias de criação com apego" ${ }^{1}$, nos faz questionar os "dispositivos de maternidade" operantes ontem e hoje; mas também os desenhos de maternagem do século XXI, que buscam conjugar, talvez de maneira impossível, aspectos da vida antes segmentados ou inexistentes para as gerações anteriores. Em função disso, a meu ver, o livro discorre para muito além da DPP, versa sobre os modos de maternagem contemporâneos e suas consequências na vida emocional e social das mulheres mães. Torna a maternidade - enquanto modelo - algo da ordem do inalcançável e fonte de adoecimento físico

I. Rosamaria Carneiro é professora associada do Departamento de Saúde Coletiva da Universidade de Brasília, orientadora no Programa de Pós-Graduação no Programa de Estudos Comparados nas Américas no Departamento de Estudos LatinoAmericanos (ELA) UnB). É doutora em ciências sociais pelo Instituto de Filosofia e Ciências Humanas da Universidade Estadual de Campinas (Unicamp). <rosagiatti@yahoo. com.br>.

1. Para entender esse conceito, acesse: <https:// www.attachmentparenting.org/ portuguese>. 
e social. Ao partir dessa perspectiva, a DPP poderia ser pensada como a ordem, enquanto regra e repetição, e não como a desordem, enquanto anomia e fuga da regra da boa mãe; no que as autoras insistem em chamar - tomando por inspiração os escritos foucaultianos - de um "dispositivo da maternidade".

A obra é organizada em três capítulos, para além da introdução e da conclusão. Dialoga com a biomedicina e a psicologia, inventaria estudos nacionais e internacionais sobre o tema e registra a fragilidade do campo, dada a quase inexistência de etnografias e trabalhos sociológicos sobre a DPP. Pontos também sustentados por Martha Militão da Silva (2016), em Significados da maternidade: um olhar antropológico sobre a experiência do pós-parto. Estudo com o qual o de Cronemberg e Franch dialoga muito em distintos campos e percepções: as duas investigações foram feitas a partir de entrevistas feitas com mulheres de camadas médias, analisadas metodologicamente como narrativas; bem como a partir de grupos on-line em redes sociais sobre DPP. Lorena e Monica trabalharam com mulheres nordestinas, do eixo Recife-João Pessoa, enquanto Martha esteve entre mulheres paulistanas. Em sua maioria, em ambas as situações, foram nove mulheres com ensino universitário, de camadas médias, com mais de 30 anos, cuja maternidade era considerada um "projeto", eminentemente planejado (Rezende, 2020). Tanto uma pesquisa quanto a outra partiram da lacuna sobre estudos sobre DPP nas ciências sociais e, em minha leitura, representam o despontar de um campo de estudos sobre o tema, quase nada explorado em nosso território acadêmico.

Lorena e Monica situam a DPP, como um estado entre ou híbrido. Entre a biologia, a oscilação hormonal e a dinâmica social à qual as puérperas são impostas. Mas também como o que fica entre o baby blues e a psicose puerperal. O primeiro seria uma tristeza ou melancolia comum e saudável bastante presente, já a última seria o caso mais grave de adoecimento psíquico, que - segundo a psicologia - representa notável perigo tanto para a mãe como para os bebês.

2. Disponível em: $<$ http://www.ensp. fiocruz.br/portalensp/informe/site/ arquivos/anexos/ nascerweb.pdf>.
$\mathrm{Na}$ introdução as autoras estabelecem alguns de seus pontos de partida conceituais, anunciando que explorarão a ideia de que quando o bebê nasce, ao contrário do que se espera, "não está tudo bem". Algo experimentado, segundo pesquisa Nascer no Brasil (2015) ${ }^{2}$, coordenada pela Fiocruz, por 25\% das mulheres depois do parto. A proposta então é olhar para o que acontece após o parto, tema que nos últimos dez anos vem sendo mais explorado na antropologia brasileira (Carneiro, 2015). Refletir sobre a DPP à luz de duas ideias, a meu ver, centrais: do "dispositivo da maternidade" e da "maternidade como projeto". Por dispositivo da maternidade as autoras compreendem todos os discursos que podem informar e assim dar contornos, a partir de modelos, regras de conduta e expectativas. Enquanto a 
maternidade como projeto advém das ideias mais recentes de uma "maternidade ativa, consciente e/ou reflexiva", todos adjetivos empregados nos últimos anos e que buscam grosso modo praticar uma "criação com apego," que problematiza o cuidado com as crianças em busca de um mundo menos violento e mais afetivo (Pulhez, 2015).

O debate ao redor da criação com apego nasce nos Estados Unidos, mas se vê difundido em países da Europa, como Espanha. Aos olhos das autoras, esse projeto tem culminado numa prática exaustiva e em "mães deprimidas", que buscam ser "mães-totais", oferecendo cama compartilhada, amamentação em livre demanda, presença amorosa em tempo integral e não terceirização dos cuidados da criança, entre tantos outros pontos. Elas veem uma correlação entre as "mães humanizadas", adeptas do parto natural e de uma criação mais natural, e as "mães deprimidas", como se um grupo derivasse do outro, partindo para tanto de uma ideia perversa de "desempenho" que casaria com a noção de "boa mãe". Nesses casos, uma mãe presente, atenta, reflexiva e "mais natural" (Carneiro, 2015). Em minha percepção, uma mãe projeto, bastante diferente da ideia de "mãe higiênica" de Freire Costa (1986), cuja tarefa era repetir ou praticar os ensinamentos dos médicos e dos padres. Nas gerações dos anos de 1970 e 1980, mães das mulheres escutadas por Lorena e Monica, os manuais de puericultura eram consultados, entendendo caber somente a replicação de tais informes e não o seu questionamento ou adequação. Esse movimento de crítica à pediatria moderna - considerada invasiva - é bastante recente e me parece compor uma proposta mais ampla que conjuga assistência ao parto e debate sobre medicalização na atualidade.

No primeiro capítulo o referencial teórico e as escolhas metodológicas são explicitados. Partem de um estudo sobre saúde mental e gênero até chegarem à DPP, considerada um padecimento feminino. Mas dialogam com mulheres que foram diagnosticadas com a depressão pós-parto e outras que assim se entenderam, por si mesmas, como "mães deprimidas". Para isso, escutaram mulheres do Recife e João Pessoa, pensando a DPP como "experiência sintetizadora"; a "maternidade" como turning point na vida dessas mulheres e a depressão pós-parto na chave das "perturbações físico-morais", justamente para escapar de qualquer noção naturalizada da maternidade e de todas as suas consequências. Foram coletadas narrativas que envolveram o que as autoras chamaram de "o antes, o pós e o sempre". Nesse sentido, escutaram sobre suas gestações e partos, para refletir como tais eventos influenciaram na DPP, bem como sobre o pós e os contornos de seu cansaço. Mas não pararam em tal ponto, investiram também em lhes perguntar sobre o que sempre se entende sobre a maternidade, com o intuito de alcançar os discursos que moldam o dispositivo da maternidade. Esse campo passa a atuar como o que dá até 
mesmo sentido às experiências vividas no antes e no pós. Optaram por "entrevistas compreensivas", que envolvem a figura da pesquisadora, vale dizer, no caso em tela, também uma mulher mãe.

O capítulo dois explora o "antes", as experiências de gestação e de parto dessas mulheres. O interessante é que essas mulheres são as que "esperaram mais" para serem mães. Em média, na casa dos 36 anos. Mas também as que buscaram um parto "mais natural" (Carneiro, 2015) e que, curiosamente, culminou numa cesárea indesejada. As autoras debatem a maternidade tardia, a noção de relógio biológico e uma ideia de maternidade que atualmente não consegue conjugar a mãe de outrora - dona de casa - com a mãe de hoje - que trabalha dentro e fora de casa. Para além disso, trazem à tona que entre as mulheres com as quais dialogaram havia o desejo de seguirem no mercado de trabalho. Elas não queriam ser "só mães". É o que comenta uma das mães durante a pesquisa: "Eu amo trabalhar. A maternidade não me completa. Não sou feliz sendo só mãe. Eu preciso trabalhar". No que antecede a DPP, despontam também as dificuldades ainda durante a gestação e pré-natal e os julgamentos ao redor de ambos os momentos, quando retomam o caso de uma gestante tabagista que não deixou de fumar e beber durante a gestação e as cobranças a ela dirigidas. Ou, de modo ainda mais marcado, quando o parto não acontece do modo desejado, quando a cesárea indesejada traz a frustração e a sensação do fracasso, a tristeza e a melancolia pelo não vivido e que não pode ser dito, já que o bebê nasceu e tem saúde.

Situações de violência obstétrica também são interpretadas como a causa para a DPP. No caso de Nix, por exemplo, disposta a viver um parto em casa, ao não ser escutada pela equipe sobre o seu desejo de ir ao hospital, viu-se em um limite pessoal que não gostaria de ter tocado e a partir de onde se sentiu muito agredida. Essa, a meu ver, pode ser uma consequência importante a ser pensada, em como o discurso do parto humanizado tem também normatizado experiências de parto como "bonitas, saudáveis e protagonizadas" a partir de um único desenho e o que pode acontecer com as mulheres que escapam a este modelo por inúmeras razões: por necessidade, por desejo e/ou por mais violência obstétrica (perpetrada até mesmo por profissionais que se dizem adeptos da humanização do parto e nascimento).

Ou seja, quais têm sido as consequências emocionais para as mulheres que não têm dado à luz de modo natural na atualidade? Em que medida esse discurso não parece compor também o dispositivo da maternidade operante em nossa sociedade do qual nos falam Lorena e Monica? Dessa maneira, o livro nos abre brechas para a reflexão sobre o ideário do parto humanizado na sociedade contemporânea e ideias de estigma, violência e diferenciação que dele parecem brotar nos 
últimos anos. Como bem pontuam as autoras, dá-se muita centralidade social ao parto, considerado um evento liminar (Turner, 1981) e um ritual de passagem (Van Gennep, 1993). Foca-se no que Emily Martin (2006) pontua como o resultado ou a "mercadoria": o nascimento do bebê.

Mas o que acontece depois desse evento, logo depois? Esta, o meu ver, é a maior contribuição desse livro tanto para as ciências sociais em geral, como também para as ciências da saúde.

Por fim chega-se ao terceiro capítulo, páginas em que a DPP é tecida para muito além da biologia e de nossos hormônios, quando é posta no cotidiano e na ordem do ordinário na vida das mulheres, ao ponto de uma das mulheres nos dizer que "a DPP é como uma doença qualquer". Torna-se sinônimo de cansaço, exaustão e fadiga e - dessa maneira - consequência da ideia de desempenho materno. Nelas a DPP é enunciada por diagnósticos médicos mas sobretudo pelas próprias mulheres. Algumas abraçam a biologia, outras entendem a tristeza sentida como natural ou aceitável para o momento em que vivem. Sendo assim, a DPP decorre do parto sonhado e não vivido, das relações com a mãe e dos conflitos geracionais, da impossibilidade de trabalhar, da solidão e dos julgamentos sociais a respeito do aleitar e de como ser uma "boa mãe". Desta feita, a DPP é nuançada e muitos passam a ser os tons sociais que a conotam. Investem no debate teórico sobre a depressão, mas logo lançam questões - a meu ver - centrais para o debate e para todo o argumento do livro (p. 102):

Em que sentido a DPP se tornou uma doença invisibilizada, apesar da alta incidência?

Em que medida a DPP pode ser reveladora do ethos de mulheres que vivenciaram a experiência puerperal?

Nessa última parte nos vemos diante de leituras asiáticas e ocidentais sobre o pós-parto, mas também retomamos os ensinamentos da cosmologia indígena (DiasScopel, 2015) e das parteiras tradicionais sobre tal evento (Fleischer, 2011). Se, no Oriente, o pós-parto é um momento de efetivo retiro, de nada fazer, no Ocidente as autoras identificam nos contextos urbanos uma ausência de sua ritualização. Entre os Mundukuru, no Amazonas, e as parteiras e mulheres do Melgaço, o resguardo parece ser vivido com mais intensidade e coletivamente, teme-se que o sangue do parto suba para a cabeça, teme-se que a criança não vingue e teme-se que a mulher adoeça. Por tudo isso, experimenta-se com mais rigor o recolhimento e os tabus que o mesmo envolve. Mães, sogras, maridos e parteiras compõem a cena de cuidados com a puérpera e com a criança. Uma composição não tão comum nos 
relatos das mulheres de Recife-João Pessoa abordadas no livro. Essas geralmente se viram sozinhas, depois de um parto desejado e não vivido, sem rede de apoio ou afeto e imersas nos ditames externos sobre a maternidade. E ainda mais: ao contrário do esperado, infelizes, tristes e cansadas. Vive-se a dificuldade em "tornar-se mãe", ao contrário de se "nascer mãe".

Desse projeto de maternidade deriva ainda a tal "culpa materna", como sentimento que mantém em pé o próprio dispositivo descrito pelas autoras. Ela vigia e se incumbe de fazer repetir um modelo de maternagem, seja o biomédico ou outro - o alternativo. Dessa maneira, a DPP pode paradoxalmente decorrer do próprio feminismo, quando este estabelece imposições de como criar e quais metas a cumprir em termos de criação e comportamento materno. Ao invés de libertar, as aprisiona, gera o cansaço e a solidão que faz adoecer.

Por todo o exposto, as autoras concluem pela necessidade de desessencialização da maternidade, haja vista a sua ideia social fazer adoecer muito mais do que os aspectos biológicos propriamente ditos. Desessencializar a imagem materna seria uma forma de promover uma vida saudável física e emocional às mulheres. Por isso, aos meus olhos, a obra em questão aborda muito mais do que a depressão pós-parto. Suas páginas nos conduzem a uma leitura crítica do modelo de maternar dos últimos tempos entre algumas das mulheres de camadas médias. Mulheres que, em nome de um parto sem intervenções e de uma criação natural, talvez tenham chegado num outro extremo: na margem em que são muitas as tarefas, horas de dedicação e saberes necessários a uma só pessoa. Na mãe que tem concentrado todas essas exigências.

Daí a DPP não ser mais uma exceção, mas tornar-se a regra, de uma conta que não fecha. É praticamente impossível ser mãe integral, manter a vida profissional e cuidar de si mesma. A pandemia tem descortinado isso (Carneiro, 2020). Por isso, talvez (nem tão talvez assim) Elisabeth Badinter (2011) estivesse totalmente certa quando - em $O$ conflito. A mulher e a mãe - anunciava que a ofensiva de uma maternidade naturalista poderia representar uma grande armadilha para o bem-viver das mulheres contemporâneas, mesmo que viesse pelas mãos do próprio feminismo. Por tudo isso, concordo integralmente com a ideia que conclui a obra:

Ser mãe é o que ela desejar ser. Se ela desejar ser. E ser mãe é, sobretudo, conseguir desnaturalizar os desejos que estão colocados como "escolhas compulsórias" às mulheres (p. 160). 


\section{Referências}

BADINTER, Elisabeth. O conflito. A mulher e a mãe. Rio de Janeiro: Record, 2011.

CARNEIRO, Rosamaria Giatti. Cenas de parto e políticas do corpo. Rio de Janeiro: Editora Fiocruz, 2015.

CARNEIRO, Rosamaria Giatti; MULLER, Elaine. Afinal, quanto de extraordinário a pandemia de covid-19 soma na vida das mulheres mães? Áltera, v. 1, n. 10, p. 441450, Jan.-Jun. 2020.

DIAS-SCOPEL, Raquel Paiva. A cosmopolítica da gestação, do parto e do pós-parto: práticas de autoatenção e o processo de medicalização entre os índios Munduruku. Brasília: Paralelo 15, 2015.

FLEISCHER, Soraya. Parteiras, buchudas e aperreios. Uma etnografia do cuidado obstétrico não oficial na cidade de Melgaço, Pará. Santa Cruz do Sul, RS: Editora Unisc, 2011.

FREIRE COSTA, Jurandir. A ordem médica e a norma familiar. Rio de Janeiro: Edições Graal, 1986.

MARTIN, Emily. A mulher no corpo: uma analise cultural da reprodução. Rio de Janeiro: Garamond, 2006.

PULHEZ, Mariana Marques. Mulheres mamíferas: práticas da maternidade ativa. Dissertação (Mestrado) - Instituto de Filosofia e Ciências Humanas, Universidade Estadual de Campinas (Unicamp), 2015.

REZENDE, Claudia Barcellos. A dor do parto: emoção, corpo e maternidade no Rio de Janeiro. Anuário Antropológico, Ano XLIV, n. 2, p.261-280, 2020. Disponível em: <http://journals.openedition.org/aa/4019; DOI: https://doi.org/10.4000/aa.4019>. Consultado em: 03 Fev. 2021.

SILVA, Martha Militão. Significados da maternidade: um olhar antropológico sobre a experiência do pós-parto. Dissertação (Mestrado) - Programa de Pós-Graduação em Ciências Sociais Universidade Federal de São Paulo (Unifesp), São Paulo, 2016.

TURNER, Victor. O processo ritual: estrutura e anti-estrutura. Petrópolis, RJ: Vozes, 1981 [1969].

VAN GENNEP, Arnold. Ritos de passagem. Petrópolis, RJ: Vozes, 1993. 
